Portland State University

PDXScholar

$11-2021$

\title{
Creating Academic-Community Partnerships to Jointly Enhance Advocacy and Research on Violence and Disability: Two Case Examples
}

\author{
Emily M. Lund \\ University of Alabama, Birmingham \\ Rosemary B. Hughes \\ University of Montana \\ Katherine E. McDonald \\ Syracuse University \\ Sandra Marie Leotti \\ University of Wyoming, sandy.leotti@gmail.com \\ Marsha Katz \\ University of Montana \\ Follow this and additional works at: https://pdxscholar.library.pdx.edu/socwork_fac

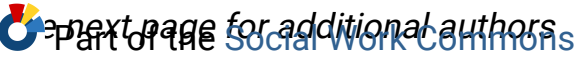 \\ Let us know how access to this document benefits you.
}

\section{Citation Details}

Lund EM, Hughes RB, McDonald KE, Leotti S, Katz MR, Beers LM, Nicolaidis C. Creating academiccommunity partnerships to jointly enhance advocacy and research on violence and disability: Two case examples. Psychological Trauma: Theory, Research, Practice, and Policy. Advance online publication. https://doi.org/10.1037/tra0001135

This Post-Print is brought to you for free and open access. It has been accepted for inclusion in School of Social Work Faculty Publications and Presentations by an authorized administrator of PDXScholar. Please contact us if we can make this document more accessible: pdxscholar@pdx.edu. 


\section{Authors}

Emily M. Lund, Rosemary B. Hughes, Katherine E. McDonald, Sandra Marie Leotti, Marsha Katz, Leanne Beers, and Christina Nicolaidis 
NOTICE: this is the author's final version of a work that was accepted for publication in the journal Psychological Trauma: Theory, Research, Practice, and Policy. Changes resulting from the publishing process, such as editing, corrections, formatting, and other quality control mechanisms may not be reflected in this document. The final, formatted version of this paper is available:

https://doi.org/10.1037/tra0001135

Creating Academic-Community Partnerships to Jointly Enhance Advocacy and Research

on Violence and Disability: Two Case Examples

\author{
Emily M. Lund, PhD, CRC \\ University of Alabama \\ Rosemary B. Hughes, $\mathrm{PhD}$ \\ Rural Institute for Inclusive Communities \\ University of Montana \\ Katherine E. McDonald, PhD \\ Syracuse University \\ Sandra Leotti, MSW, PhD \\ University of Wyoming \\ Marsha R. Katz, MEd \\ Leanne M. Beers, PhD \\ University of Montana \\ Christina Nicolaidis, MD, MPH \\ Portland State University
}




\section{Oregon Health Science University}

Author's note: Correspondence regarding this article should be directed to Emily M. Lund, PhD, at emlund@ ua.edu / emily.m.lund@gmail.com or Emily Lund, Department of Educational Studies in Psychology, Research Methodology and Counseling, PO Box 870231, University of Alabama, Tuscaloosa, AL 35487. The Men's SSP project was funded by National Institute on Disability and Rehabilitation Research (NIDRR) grant H133G070190. The Partnering project was funded by the Centers for Disease Control and Prevention (CDC), National Center on Birth Defects and Developmental Disabilities (NCBDDD) under Cooperative Agreement U01DD000231 to the Association of University Centers on Disabilities (AUCD). The award was made to the University of Montana. The content of this manuscript does not necessarily reflect the views and policies of CDC, NCBDDD, NIDDR, nor AUCD. The grants did not provide project assistance beyond research funding.

Conflicts of interest: The authors have no conflicts of interest to declare.

\section{Data transparency statement}

Previous articles on both of the two studies used as case examples in this paper discuss the research results (Hughes et al., 2019; Lund et al., 2015; Platt et al., 2017; Oschwald et al., 2015), study processes (Lund et al., 2015; Nicolaidis et al., 2015, 2019, 2020; Oschwald et al., 2014), or evaluation results (McDonald \& Stack, 2016; Stack \& McDonald, 2018). This article differs from previous articles on these projects because it focuses on the ways in which issues and advocate concerns at the specific intersection of disability and violence were addressed during both studies; this focus on advocacy related to violence-specific topics has not been addressed in previous articles. Additionally, this article is unique among them in that it re-centers the CBPR processes to focus on specifically on advocacy for violence-related issues and concerns in disability communities, which have not been addressed in the previous articles. Finally, this article discusses how different CBPR processes were used to identify and address common advocate concerns in two previously unconnected studies on violence and disability that had markedly different project aims and goals (measurement adaptation and intervention development).

Note on language: In accordance with broader trends and preferences in the disability community (Andrews et al., 2019), we use a mixture of person-first and identity-first language to refer to people with disabilities in general. In accordance with the preferences of the autistic community, we use identity-first language exclusively to refer to autistic adults (Bottema-Beutel et. al, 2021). 


\begin{abstract}
Objective: This article describes the use of community-based participatory research (CBPR) to foster bidirectional and equitable academic-community partnerships in two studies related to interpersonal violence and disability. Methods: We analyzed our methods and experiences in conducting these studies to focus on the ways in which CBPR methodology was used to jointly promote and enhance research and advocacy surrounding violence and disability in the research processes themselves and the resulting assessment and intervention products. Results: Our use of CBPR methodology allowed us to identify and address critical issues related to violence in the disability community, such as disability-related forms and experiences of violence, concerns and barriers linked to mandated reporting laws, and inaccessible measures and interventions, and to address them in research products. Additionally, our bidirectional academic-community partnerships led us to address overall accessibility of the research process itself as a means by which to amplify advocate voices in science. Conclusions: Full, meaningful, and equitable participation of people with disabilities at every stage of the research process allows for the creation of partnerships that jointly advance research and advocacy around violence and disability.
\end{abstract}

Keywords: violence; disability; community-based participatory research (CBPR); accessibility; advocacy

\title{
Clinical Impact Statement
}

Despite being at higher risk for violence, people with disabilities are often left out of academic conversations around violence, and their experiences and concerns go unheard. In order to address this, academic researchers partnered with community members with disabilities to create 
accessible assessments and interventions that addressed the lived experiences of violence in disability communities. Community members and academic researchers were equally involved throughout all parts of both studies, and both community members and researchers felt that the studies themselves and the assessments and interventions that came from them benefitted both research and advocacy around violence and disability.

Note on language: In accordance with broader trends and preferences in the disability community (Andrews et al., 2019), we use a mixture of person-first and identity-first language to refer to people with disabilities in general. In accordance with the preferences of the autistic community, we use identity-first language exclusively to refer to autistic adults (Bottema-Beutel et al., 2021). 


\section{Creating Academic-Community Partnerships to Jointly Enhance Advocacy and Research on Violence and Disability: Two Case Examples}

People with disabilities have long been targets of violence in a multitude of forms, including bullying and harassment, interpersonal violence, and severe assault and murder (Petersilia, 2001). Modern studies similarly indicate that disabled people experience high rates of violence victimization and are more likely to be victims of interpersonal violence and abuse than their non-disabled peers. For example, R. Hughes and colleagues (2011) found that the lifetime prevalence of interpersonal violence in 21 studies conducted in the United States and Canada ranged from $26.0 \%-90.0 \%$ for women with disabilities and $28.7 \%$ to $86.1 \%$ for men with disabilities. In terms of comparative data, K. Hughes and colleagues (2012) found that adults with disabilities were 1.5 times more likely than those without disabilities to experience abuse in a 26-study meta-analysis. The increased risk is generally seen across disability types (Hughes et al., 2011), although people with developmental and psychiatric disabilities are at even higher risk (Hughes et al., 2012). Disability also often occurs before violence occurs (Breeding \& Armour, 2015), establishing disability as a risk factor for victimization.

Despite the strong persistence of violence against people with disabilities, people with disabilities themselves have historically been excluded from the academic, research-focused conversation on violence and disability (Brown, 2017; Mueller et al., 2019) due to ableist exclusion. This has led to disconnect between research and advocacy on violence and disability-the concerns and experiences of people with disabilities are often not reflected in research, and research does not necessarily address the needs and experiences of the disability community (Lund et al., 2017). This limits the ability of researchers to meaningfully understand and prevent violence victimization and the negative effects thereof in people with disabilities. 
Community-based participatory research (CBPR) is one approach for addressing gaps between community needs and research endeavors. CBPR relies on active, engaged, equitable stakeholder involvement in all stages of the research process (Israel et al., 2013). It centers the needs of the target community (in this case, people with disabilities) throughout the research process address their expressed needs and to produce data and products that are accessible, applicable, and relevant for the target community. In doing this, academic and community partners collaborate to create meaningful and sustainable change in the community (Israel et al., 2013). CBPR strives to include academic researchers and community members as equal partners throughout all stages of the research process, including the determination of goals, methods, and dissemination strategies, as well as the creation of study materials and products, such as assessments and interventions (Hughes et al., 2020; Nicolaidis \& Raymaker, 2015). This allows community members to advocate for issues that are important to their communities throughout the research process and for those issues to be reflected in the study goals, methods, and products. Teams who use a CBPR approach need to actively focus on power dynamics and create infrastructures, policies, and practices that enable shared decision-making (Nicolaidis et al., 2019). Discussions between stakeholders and researchers continue until consensus is reached and all parties agree that the strategy decided upon is appropriate, meaningful, rigorous, and addresses community needs (McDonald \& Stack, 2016). CBPR is particularly important when working with historically marginalized populations, such as people with disabilities, who may be traditionally excluded from academic spaces, silenced, or distrust researchers (Israel et al., 2013).

In addition to the CBPR studies with autistic adults mentioned above (e.g., Nicolaidis \& Raymaker, 2015; Nicolaidis et al., 2019), CBPR has been used successfully to study issues such as health and disability (Vaughan et al., 2020), higher education experiences of autistic students 
(Wright \& Diener, 2020), and program evaluation at domestic violence shelters (Nnawulei et al., 2019). Common themes include the importance of building trust (Nnawulei et al., 2019) and receiving community feedback on instrumentation and goals (Vaughan et al., 2020; Wright \& Diener, 2020;). Above all else, the importance of building a space in which community members have a sense of joint ownership of the process and feel able to give feedback and guidance freely is paramount in successful CBPR processes (Nicolaidis et al., 2019; Nnawulei et al., 2019; Vaughan et al., 2020; Wright \& Diener, 2020). CBPR creates a meaningful on-going dialogue between community members and academic researchers, allowing academic-community partnerships to focus on issues that are important to the community (i.e., advocacy for community needs). Moreover, the active involvement of community members improves the quality of the research by ensuring that research protocols and data collection materials are accessible and culturally appropriate (Brett et al., 2014; Nicolaidis et al., 2020). Equitable, ongoing community engagement has the potential to increase the overall impact of the research and resulting data and products.

In this article, we discuss examples of two CBPR-based projects addressing violence among people with disability: a) an intervention development project (the Men's Safer and Stronger Program [Men's SSP]; Lund et al., 2015; Oschwald et al., 2015) and b) a crosssectional measurement adaptation and survey study (the Partnering with People with Developmental Disabilities to Address Violence project [Partnering Project]; Hughes et al., 2019; McDonald \& Stack, 2016; Nicolaidis et al., 2105; Oschwald et al., 2014; Platt et al., 2017; Stack \& McDonald, 2018) to illustrate how a CBPR approach was used to mutually benefit both advocacy and research on violence against people with disabilities through continuous, equitable, and bidirectional partnerships. All examples used in this article are from these two projects. 


\section{Project Descriptions}

\section{Men's Safer and Stronger Program}

The Men's SSP was a program development study with the aims of developing (Lund et al., 2015) and pilot-testing (Lund et al., 2015; Oschwald et al., 2015) a web-based abuse and safety education and screening program specifically for men with disabilities that used audio computer-assisted self-interview (A-CASI) technology. The Men's SSP project featured information on different types of abuse, warning signs, safety planning tips, resources, and interviews with male violence survivors with disabilities. The project had three main developmental phases: 1) understanding stakeholder needs; 2) program development and revision; and 3) expert review by men with disabilities. Following expert review and related revisions, a small pilot study was also conducted (Oschwald et al., 2015) that included collecting participant feedback and usability data (Lund et al., 2015). In this study, "disability" was broadly defined to include any chronic physical or mental condition that limits functioning in activities of daily living (Americans with Disabilities Act, 1990); men who identified as Deaf but not disabled were also included. As a result, men with a diverse range of physical, intellectual, psychiatric, developmental, and sensory disabilities (many of whom had experienced interpersonal violence) served on the project team through all phases of the project. Some of these men were part of the academic research staff while others served in non-academic roles such as consultants, content creators, guides, advisors, and expert reviewers during different stages of the project (Lund et al., 2015); the academic research staff that worked on the project also included some women with disabilities.

The project focused on men with disabilities because their experiences, and intersectional experiences in general (Lund et al., 2017), are often understudied in violence and disability 
research (Hughes et al., 2011). To this point, our community partners in this study frequently discussed the ways in which social norms about masculinity, disability, and violence intersect to produce unique challenges for men with disabilities who experience violence (Lund et al., 2015).

\section{The Partnering Project}

The Partnering Project was a cross-sectional study of abuse and health in adults with developmental disabilities (Hughes et al., 2019; Nicolaidis et al., 2105; Oschwald et al., 2014; Platt et al., 2017). As part of the Partnering Project, an independent evaluation of the CBPR process was also conducted (McDonald \& Stack, 2017; Stack \& McDonald, 2018). Because of the inaccessibility of most commonly used instruments used in both violence and health research (Nicolaidis et al., 2020; examples also discussed below), a major aim of the project was to develop a maximally accessible survey of violence victimization and physical and mental health outcomes that could be used by people with developmental disabilities. Doing so involved both the adaptation of survey instruments (Nicolaidis et al., 2015); and the use and further development of A-CASI technology (Oschwald et al., 2014).

For the purposes of the Partnering Project, "developmental disability" was broadly defined as any severe, life-long disabling condition that began before age 22 and substantially limited functioning in at least three major life activities (e.g., communication, learning, mobility, sensory input and processing, self-care) (Developmental Disabilities Assistance and Bill of Rights Act, 2000). Thus, the developmental disability community included people with physical and sensory disabilities that developed during childhood as well as autistic adults and individuals with intellectual, cognitive (e.g., brain injury), language (e.g., expressive and receptive language disorders), and learning (e.g., dyslexia) disabilities. Participants of all sexes and gender identities were eligible to participate. People with developmental disabilities were involved in all stages of 
the project, both as active members of the project steering committees, and as members of the two Community Advisory Boards (CABs). The steering committee, which was made up of both academic researchers and community partners, jointly governed all aspects of the project; the CABs met regularly to review and adapt measures, procedures, and other plans for the study. Although some service providers and family members were also represented on the CABs, the focus was on direct involvement of people with developmental disabilities, including people whose disabilities may have required a higher level of support, been judged as more "severe," or affected communication in way that might have excluded them in traditional research or advisory roles. Effort was also made to include both academic researchers and community members from multiply marginalized backgrounds, such as disabled people of color and queer disabled people, on the project team. Additionally, because a specific focus of the study was on rural-urban differences in violence victimization and health within disability communities, the project team included community members from both rural and urban areas.

\section{General Accessibility Issues}

\section{The Research Process}

Many of the common practices that researchers use in planning and conducting research, such as scientific language and communication styles (e.g., using only oral or only written communication) within a project team, may themselves exclude participation by people with disabilities. In order to create maximally accessible research environments, the project teams for both studies made every effort to accommodate the needs of academic and community partners with disabilities and respond to their advocacy in this area. For example, during the expert review phase of the Men's SSP, some expert reviewers advocated for the ability to choose realtime text chat instead of real-time spoken commentary to provide feedback on the program. This 
advocacy for change in the research process allowed for greater access by and participation of community members who would not have been able to give spoken feedback, thereby providing the research team with feedback from a segment of the disability community whose input would have traditionally been excluded. As another example, plain language summaries of processes, next steps, action items, and decisions made during the Partnering Project meetings were created to help ensure that individuals with intellectual and language-based disabilities could be fully informed and engaged with the research process. Pre-meetings were also used to allow project team members to receive and process content in advance of full meetings, increasing access for team members whose disabilities resulted in difficulties rapidly processing and responding to new information. Similarly, project team emails were structured with clearly labeled sections on next steps, required actions, and deadlines in order to accommodate team members whose disabilities required more concrete and structured narratives.

The goal of these structural changes to the research process itself was to ensure that team members with disabilities could be meaningfully involved in all stages of the process and provide input and guidance on all aspects, allowing advocacy for community needs to permeate the research process. Only consulting individuals with disabilities for a quick "rubber-stamping" of research materials or products at the end of the development process would not have represented true community involvement and would not have allowed us to address many of the issues that our community partners brought to our attention. Similarly, excluding team members with certain disabilities from the project team would have meant both that those perspectives were silenced and that our research products would not have been vetted by a member of that community, diminishing the quality of the ensuing research and advocacy.

\section{Research Product Accessibility}


Research measures and intervention programs are largely developed with the assumption that the participants who interact with them will have full use of sight and hearing and typical motor, cognitive, and language abilities. For example, a survey that uses a pencil and paper data collection format reflects the assumption that all potential participants can read printed text and manually circle answers and thus would exclude individuals who are blind, have difficulties in reading, or cannot physical circle answers. Similarly, standardization processes for measures typically do not include individuals with language, cognitive, or intellectual disabilities in standardization samples, so it is not clear to what extent—if any-those measures may be valid for those populations (Nicolaidis et al., 2020). Regrettably, the approach to such accessibility concerns is often to simply exclude participants with disabilities and to rely on proxy report from caregivers or family members (Nicolaidis et al., 2020). Such practices exclude people with disabilities from research, silencing their lived experiences and hampering their advocacy around critical issues that affect their communities. Thus, creating accessible products—both measures and interventions - results in bidirectional benefit among researchers and community members. Community members are able to share their experiences via research participation (enhancing advocacy around issues of importance to their communities), and academic researchers are able to access data that may not have been previously available (enhancing the scope and quality of their data).

Our process for creating accessible research products relied on a combination of preexisting knowledge about disability accessibility (e.g., screen-reader accessibility, physical accessibility of computer components) and extensive involvement of our community partners, who identified many potential issues with language and content delivery and helped develop accessible solutions and alternatives. As mentioned, many of the strategies we developed to fully 
include community members with disabilities on our project teams also influenced our development of the research products themselves, and concerns raised by community members allowed us to modify our products to address identified barriers specific to the study of violence. Some of these barriers and how we addressed them are described below.

\section{Violence-specific Issues Addressed with CBPR}

\section{Identifying Community Experience and Needs}

Researchers have noted that disability-related needs and experiences may impact the ways in which disabled people experience violence (Lund et al., 2019; McFarlane et al., 2001; Saxton et al., 2001, 2006). For example, people with disabilities may encounter specific, disability-related forms of abuse that people without disabilities are unlikely to experience, such as denial of care or assistance with activities of daily living (e.g., toileting, feeding, dressing) or destruction of equipment or assistive technology (e.g., wheelchairs, walkers, canes, communication devices) (Lund et al., 2019; McFarlane et al., 2001; Nosek et al., 2001). They may also experience unique topographies of more common forms of abuse due to their disability. For example, people with disabilities who require support with finances for physical or cognitive reasons may experience financial abuse in the form of theft of Social Security payments or a support person taking extra money from the teller machine when helping a disabled individual use their debit card (Lund et al., 2015). Likewise, individuals rely on mobility aids can be physically confined by the removal of those aids (Saxton et al., 2001, 2006). Because these disability-specific experiences of abuse are much less likely to be encountered by the general population, they are typically not included in most measures of violence victimization and thus are not reported in many studies (Hughes et al., 2011). In order to address these potential 
omissions, we made listening to the lived experiences of people with disabilities a foundational step in both projects, as described below.

Men's SSP. The first phase of the Men's SSP process involved both individual interviews and focus groups with men with disabilities who had experienced violence (Lund et al., 2015). Participants in both processes were asked open-ended questions about their experiences of violence, experiences that they knew other men with disabilities had encountered, and specific topics that they thought were important for the Men's SSP to address. This process allowed for the project team to develop the content in the second phase of the project in a way that reflected both empirical research and the advocacy of disabled male survivors of abuse, rather than simply assuming that the men's experiences would reflect our existing ideas and assumptions about the experience of abuse.

This philosophy of combining advocacy and research continued throughout the other two phases of the project. During the program development phase, we interviewed several men with disabilities about their experiences of abuse and structured the program around these narratives. Each man was invited and encouraged to review the transcript and video of his interview to ensure that it accurately reflected his experiences; each man also reviewed and approved edits of his story and was given final creative control over what content was used in the program. As with the individual interviews in the first phase of the project, questions were intentionally broad and men were encouraged to - and supported in — sharing their experiences of abuse and resiliency in their own words. In this way, the project allowed men to advocate for their community by sharing their experiences in order to help other men with disabilities who may be experiencing similar violence victimization. Finally, in the expert review phase, men with disabilities were asked to provide running commentary as they went through the Men's SSP and 
note both technological and accessibility concerns as well as areas where content was missing, unclear, or otherwise not reflective of their experiences and community needs. Again, expert review feedback was highly valued and incorporated into the final version of the Men's SSP program to further amplify advocate voices and better reflect the lived experiences and advocacy of men with disabilities.

Partnering Project. Just as the Men's SSP project started with the assumption that the experiences of people with disabilities were needed to inform the core content of the intervention, the Partnering Project began with the assumption that measures of violence victimization and health outcomes needed to truly reflect the experiences of people with disabilities, including the types of abuse included in our measures and the language used to describe these experiences. Some words and terms that are commonplace in violence research may not be as readily understandable to people with disabilities, either because they are too complex or too vague (Nicolaidis et al., 2020). Thus, the responses that research participants with disabilities give to these items may not reflect their lived experiences. In order to address this issue, $\mathrm{CAB}$ members and steering committee members worked together to review every measure and item and brainstorm ways to increase the clarity and understandability without changing the core meaning of the item. Strategies for doing this included adding examples of a certain type of behavior (e.g., for what constitutes sexual abuse or physical abuse) that participants may have experienced and adding hotlinks that allowed participants to see the definition or examples of a particular term (Nicolaidis et al., 2015, 2020). We also used existing measures that asked about disability-related abuse in particular (e.g., the Abuse Assessment Screen-Disability; McFarlane et al., 2001) to ensure our measures fully captured a broader range of possible experiences with abuse. As with all measures, these items were also vetted by $\mathrm{CAB}$ 
members to ensure relevance and improve understandability, reflecting the full involvement of community partners in the measurement adaptation and approval process.

\section{Addressing Confidentiality and Safety}

People with disabilities are often considered "vulnerable adults" under mandated reporting laws that require adult protective services (APS) to be contacted if abuse is suspected or reported (Lund, 2020). Researchers have found that these laws often make people with disabilities hesitant to disclose abuse out of fear of APS involvement (Oschwald et al., 2009; Saxton et al., 2001, 2006). These individuals often express concern that such involvement could make their situation worse as opposed to better and possibly result in a loss of their independence or retaliation from a perpetrator (Curry et al., 2011; Saxton et al., 2001, 2006). As a result, individuals with disabilities may refrain from participating in violence-related research or misrepresent their experiences of abuse in order to avoid triggering a mandatory report. Similarly, researchers may refrain from recruiting participants who would fall under their state's mandatory reporting guidelines in order to avoid the legal and ethical issues associated with potential mandatory reporting, or refrain from asking questions that would trigger mandatory reporting. This common desire of researchers and institutional review boards to avoid ethicallegal issues that can arise with mandated reporting and with the inclusion of participants who may be considered "vulnerable" or "cognitively impaired" in general (Hughes et al., 2010) again excludes and marginalize the experiences of people with disabilities, particularly disabilities judged more "severe," in research. As a result, these participants' experiences are often not reflected in the results or conclusions of studies, silencing advocate voices and creating gaps in the scientific record. 
In both projects, we made a concentrated effort to facilitate the full involvement of people with disabilities and respect their rights to privacy and self-determination while still upholding ethical and legal principles and standards regarding their safety. One of the primary means that we used to do this was the use of accessible A-CASI technology. The A-CASI technology allows individuals to access the content in a variety of ways, including screen readers for people who are blind or visually impaired, text-to-speech read-aloud options for individuals who struggle to read printed text, American Sign Language (ASL) video for Deaf and hard of hearing individuals for whom ASL is their primary language, and standard written text, which individuals could enlarge or highlight as needed (for visual examples, see Oschwald et al., 2014). Participants were also provided with headphones so that any researchers present could not overhear any text being read, including participants' responses to items about abuse (Lund et al., 2015; Oschwald et al., 2014).

One of our goals in providing these multiple access options was to make it possible for individuals with a variety of disability access needs to complete the programs and surveys without assistance from another person so that the data could be truly anonymous and mandatory report would not be triggered. In this way, we could both respect participants' autonomy and confidentiality and address a persistent potential barrier to accurate data collection and full participation that was identified in both these studies and previous ones (e.g., Oschwald et al., 2009). If participants did request assistance from another person while completing the program, research assistants offered to turn away from the screen and stop listening during the sections of the survey related to abuse experiences and reminded participants again about mandatory reporting guidelines. If a mandatory report did have be made, participants were invited to be involved in the process, allowing them to tell their story, rather than having it be told for them, as 
so often happens to people with disabilities. In this way, our process reflected the core disability rights principle of self-determination, a principle strongly held by both the community members and academics on the project teams.

In addition to mandatory reporting and confidentiality issues, both project teams had to address the issue of participant safety in with regards to caregivers and the need for assistance. Many people with disabilities depend on the perpetrators of their abuse for assistance with daily life activities, something that has been both reflected in the previous literature (Powers et al., 2008; Saxton et al., 2001, 2006) and was echoed by our participants and partners in these studies (Lund et al., 2015). This means that taking a flier or being seen reading or listening to an announcement about violence research could likely put some participants in danger of retaliation by a perpetrator. In order to address these issues, both the Men's SSP and Partnering Project were advertised using more general terms such as "health" and "safety" in recruitment-related communication in order to avoid a direct connection with violence and abuse that may have kept some individuals from safely engaging with our recruitment announcements. Additionally, we provided highly trained, disability-competent research assistants to assist with any accessibility or technical barriers during the research process, thus allowing participants to take part in the process without a support provider present even if they might have needed assistance in a standard research or intervention setting.

\section{Feedback on Our Process and Products}

Overall, the intensive CBPR process that we used in these studies appeared to benefit both research and advocacy bidirectionally. In the independent evaluation of the CBPR process for the Partnering Project, both community and academic researchers emphasized that the project had a sense of shared leadership, true partnership, and co-learning (McDonald \& Stack, 2016; 
Stack \& McDonald, 2018), reflecting a bidirectional and mutual researcher-advocate growth process. Expert reviewers from the Men's SSP reported a similar sense of engagement and felt that their experiences and opinions were heeded and reflected during the CBPR process and in the final product (Lund et al., 2015). Participants and team members from both projects indicated that they derived a sense of empowerment from participating in them, both in terms of advocating for themselves and advocating for their communities (Lund et al., 2015; McDonald \& Stack, 2016; Stack \& McDonald, 2018).

This sense of engagement and purpose appeared to transfer to participants who were not involved in the research process but participated in the resulting studies. For example, over $80 \%$ of the 350 participants in the Partnering Project study reported being glad that they participated in the study, with almost $90 \%$ agreeing that the topics covered in the survey were very important (Oschwald et al., 2014). Likewise, both qualitative and quantitative feedback from the Men's SSP pilot indicated that men who participated in the pilot found the information to relevant and helpful. All of the 31 participants reported that it would be a lot or quite a bit helpful to other men with disabilities, and qualitative feedback indicated that the men found the content to be reflective of their needs and experiences with disability and violence (Lund et al., 2015), suggesting that our project successfully captured the lived experiences of disability advocates.

In terms of the research products developed, the measures of violence used in both studies were found to have adequate to excellent reliability (Hughes et al., 2019; Nicolaidis et al., 2015; Oschwald et al., 2015). This suggests both that people with disabilities can be accurate reporters of their own experiences with violence and that making small changes to make measures more accessible and understandable to participants with disabilities does not negatively impact their psychometric quality. Additionally, participants in both studies preferred the A- 
CASI format over other options (e.g., hardcopy, face-to-face interviews) and found the system to be an effective, disability accessible, and safe means by which to obtain information and answer questions about violence (Lund et al., 2015; Oschwald et al., 2014). Overall, the products created in these studies appear to be acceptable and meaningful to people with disabilities.

\section{Implications}

This article provides two examples of CBPR processes in which a bidirectional relationship was created between violence researchers and individuals with disabilities in order to jointly promote research and advocacy. A truly equitable, participatory CBPR process requires both time and openness from all involved. Academic researchers must be willing to listen to lived experiences and needs of advocates with disabilities and build their research process from the ground up, rather than assuming that they know what the disability community needs due to academic or professional knowledge and training. Likewise, non-academic advocates need to understand the basics of the research process and research ethics, such as legal requirements for mandated reporting and limitations for how much an existing measure can be changed, and take such considerations into account in their suggestions. This consensus process can be lengthy and time-intensive, requiring multiple iterations before a product is approved by all parties. By prioritizing true community engagement, academic researchers actively signal that progress and inclusion needs to be a core component of the research process, not an afterthought. However, a less intensive process of consultation and feedback from community experts may still be helpful in the event that a full CBPR process is not feasible for a given project (Nicolaidis et al., 2020).

When discussing academic-community partnerships, it is also important to note that the academic and disability communities are not mutually exclusive. In both of the projects discussed here, some academic members of the team, including some members of the senior 
project staff, also had disabilities, and some community members who were not serving in academic research roles on the projects had research training and experience. There is a critical need for disability researchers with lived experience of disability (Andrews et al., 2019), and it is vital that non-disabled researchers mentor and advocate for students and early career researchers with disabilities (Lund et al., 2020). It is also important to involve disabled community members and advocates with no research training or academic experience, as it can be difficult for such individuals to have their experiences and ideas heard (Nicolaidis et al., 2019).

\section{Suggestions for Researchers}

Over the course of these two projects, we learned important lessons that may be helpful in guiding researchers who are interested in using a CBPR approach to study violence against people with disabilities. First, a true CBPR process will be inherently time-consuming. In order for the academic-community partnership to truly function, academic and community partners need to have time to engage in iterative processes in which partners from both groups can raise concerns and make modifications to instruments, measures, and procedures. This time will need to be built into the research process, including proposed budgets and timelines in grant applications. Second, academic researchers must be willing to see community partners as truly equal partners. Given their scholarly expertise, academic researchers might have initial difficulty accepting community partner feedback that certain measures or methods are inaccessible or offensive to people within disability communities. Academic researchers must be open to the idea that our accepted measures, methods, and interventions have been largely developed without the involvement of disabled individuals and thus are often unintentionally inaccessible or ableist. Third, academic researchers need to understand the people with disabilities have experienced considerable ableism that shapes their experiences with and trust of the academic process and 
society at large. Thus, academic researchers should be willing to form long-term community connections with individuals from disability communities in order to gain credibility and trust. Such long-term relationships will also allow academic researchers to receive community input on topics of interest and importance to the disability community and thus to engage in more socially valid research.

\section{Limitations}

This article describes two studies with overlapping research teams, both of which have a long history of positive involvement with local disability communities and included researchers with disabilities on the project teams. This may have made it easier for us to gain the trust of community members. Additionally, we had financial and resource support from large grants, allowing us to invest substantial time and money into the CBPR process. These resources may not be available to new or unfunded researchers, potentially making full engagement in CBPR more difficult.

\section{Conclusion}

Despite being disproportionately likely to be victims of violence, people with disabilities have often been excluded from violence research due to the inaccessibility of research processes and products as well as ableist assumptions made by researchers. Community-based participatory research provides a means by which people with disabilities can be involved in violence research in active and meaningful ways. A willingness to truly partner with people with disabilities can create mutually beneficial bidirectional relationships that enhance both research and advocacy related to violence and disability. 


\section{References}

Americans with Disabilities Act of 1990, 42 U.S. C. A. § 12101 et seq. (West 1993)

Andrews. E. E., Forber-Pratt. A. J., Mona, L. R., Lund, E. M., Pilarski, C. R,, \& Balter, R. (2019). \#SaytheWord: A disability culture commentary on the erasure of 'disability'. Rehabilitation Psychology, 64, 111-118.

Bottema-Beutel, K., Kapp, S. K., Lester, J. N., Sasson, N. J., \& Hand, B. N. (2021). Avoiding ableist language: Suggestions for autism researchers. Autism in Adulthood, 3(1), 18-29.

Brett, J. O., Staniszewska, S., Mockford, C., Herron-Marx, S., Hughes, J., Tysall, C., \& Suleman, R. (2014). Mapping the impact of patient and public involvement on health and social care research: A systematic review. Health Expectations, 17(5), 637-650.

Breiding, M. J., \& Armour, B. S. (2015). The association between disability and intimate partner violence in the United States. Annals of Epidemiology, 25(6), 455-457.

Brown L. X. Z. (2017). Ableist shame and disruptive bodies: Survivorship at the intersection of queer, trans, and disabled existence (p. 163-178). In A. J. Johnson, J. R. Nelson, \& E. M. Lund (Eds.), Religion, disability, and interpersonal violence. Cham: Springer.

Curry, M. A., Renkor, P., Robinson-Whelen, S., Hughes, R. B., Swank, P., Oschwald, M., \& Powers, L. E. (2011). Facilitators and barriers to disclosing abuse among women with disabilities. Violence \& Victims, 26, 430-444. doi: 10.1891/0886-6708.26.4.430

Developmental Disabilities Assistance and Bill of Rights Act of 2000. 42USC 15001. Publ Law, 106-402 (2000). https://www.acl.gov/sites/default/files/about-acl/201612/dd_act_2000.pdf 
Hughes, K., Bellis, M. A., Jones, L., Wood, S., Bates, G., Eckley, L., .. \& Officer, A. (2012). Prevalence and risk of violence against adults with disabilities: A systematic review and meta-analysis of observational studies. The Lancet, 379(9826), 1621-1629.

Hughes, R. B., Lund, E. M., Gabrielli, J., Powers, L. E., \& Curry, M. A. (2011). Prevalence of interpersonal violence against community-living adults with disabilities: A literature review. Rehabilitation Psychology, 56(4), 302-319.

Hughes, R. B., Robinson-Whelen, S., Goe, R., Schwartz, M., Cesal, L., Arnold, K., Hunt, T., McDonald, K. E., \& the Safety Project Consortium. (2020). "I really want people to use our work to be safe" ... Using participatory research to develop a safety intervention for adults with intellectual disability. Journal of Intellectual Disabilities, 24(3), 309-325.

Hughes, R. B., Robinson-Whelen, S., Pepper, A., Gabrielli, J., Lund, E. M., Legerski, J., \& Schwartz, M. (2010). Development of a safety awareness program for women with diverse disabilities. Rehabilitation Psychology, 55, 263-271.

Hughes, R. B., Robinson-Whelen, S., Raymaker, D., Lund, E. M., Oschwald, M., Katz, M., ... \& Larson, D. (2019). The relation of abuse to physical and psychological health in adults with developmental disabilities. Disability and Health Journal, 12(2), 227-234.

Israel, B. A., Eng, E., Schulz, A. J., \& Parker, E. A. (2013). Introduction to methods for CBPR for health. In Methods for community-based participatory research for health (pp. 3-38). Jossey-Bass.

Levine, A., \& Breshears, B. (2019). Discrimination at every turn: An intersectional ecological lens for rehabilitation. Rehabilitation Psychology, 64(2), 146-153. 
Lund, E. M., Corr, C., Kinavey, E., Mott, K., Chowdhury, D., Hammond, M., Thomas, K. B., \& Schultz, J. C. (2019). Retrospective childhood disability-related abuse: A proof of concept study. Journal of Interpersonal Violence. Available via online ahead of print. doi: https://doi.org/10.1177/0886260519879240

Lund, E. M., Nelson, J. R., \& Johnson, A. J. (2017). Keeping an open door: Past problems, best practices, and future directions for working with interpersonal violence survivors with disabilities (pp. 225-228). In A. J. Johnson, J. R. Nelson, \& E. M. Lund (Eds.), Religion, disability, and interpersonal violence. New York: Springer.

Lund, E. M., Oschwald, M. M., Latorre, A., Hughes, R. B., Liston, B., Shelton, R., Flaherty, M. C., Porcher, E. M., \& Powers, L. E. (2015). Developing an internet-based abuse awareness program for men with disabilities. Rehabilitation Counseling Bulletin, 58(3), $131-145$.

Lund, E. M., Wilbur, R. C., \& Kuemmel, A. M. (2020). Beyond legal obligation: The role and necessity of the supervisor-advocate in creating a socially just, disability-affirmative training environment. Training and Education in Professional Psychology, 14(2), 92-99.

McDonald, K. E., \& Stack, E. (2016). You say you want a revolution: an empirical study of community-based participatory research with people with developmental disabilities. Disability and Health Journal, 9(2), 201-207.

Mueller, C.O., Forber-Pratt, A.J., \& Sriken, J.F. (2019). Disability: Missing from the conversation of violence. Journal of Social Issues, 75(3), 707-725. 
Nicolaidis, C., Raymaker, D., McDonald, K., Dern, S., Ashkenazy, E., Boisclair, C., ... \& Baggs, A. (2011). Collaboration strategies in nontraditional community-based participatory research partnerships: Lessons from an academic-community partnership with autistic selfadvocates. Progress in Community Health Partnerships, 5(2), 143.

Nicolaidis, C., \& Raymaker, D. (2015). Community Based Participatory Research with communities defined by race, ethnicity, and disability: Translating theory to practice. In The SAGE Handbook of Action Research (pp. 167-178). Thousand Oaks, CA: Sage Publications, LTD.

Nicolaidis, C., Raymaker, D., Kapp, S. K., Baggs, A., Ashkenazy, E., McDonald, K., .. Joyce, A. (2019). The AASPIRE practice-based guidelines for the inclusion of autistic adults in research as co-researchers and study participants. Autism, 23(8), 2007-2019.

Nicolaidis, C., Raymaker, D., Katz, M., Oschwald, M., Goe, R., Leotti, S., . . Hughes, R. B. (2015). Community-based participatory research to adapt health measures for use by people with developmental disabilities. Progress in Community Health Partnerships: Research, Education, and Action, 9(2), 157-170.

Nicolaidis, C., Raymaker, D. M., McDonald, K. E., Lund, E. M., Leotti, S., Kapp, S. K., ... \& Hunter, M. (2020). Creating accessible survey instruments for use with autistic adults and people with intellectual disability: Lessons learned and recommendations. Autism in Adulthood, 2(1), 61-76.

Nosek, M.A., Foley, C.C., Hughes, R.B., \& Howland, C.A. (2001). Vulnerabilities for abuse among women with disabilities. Sexuality and Disability. 19(3), 177-189. 
Oschwald, M., Leotti, S., Raymaker, D., Katz, M., Goe, R., Harviston, M., . . Nicolaidis, C. (2014). Development of an audio-computer assisted self-interview to investigate violence and health in the lives of adults with developmental disabilities. Disability and Health Journal, 7(3), 292-301.

Oschwald, M. M., Lund, E. M., Latorre, A., Shelton, R., Hughes, R. B., Liston, B., Flaherty, M. C., \& Powers, L.E. (2015). An exploratory study of a computer-assisted abuse awareness and safety planning program for men with disabilities: The Men's Safer and Stronger Program. Journal of Social Work in Disability \& Rehabilitation, 14(2), 88-109.

Oschwald, M., Renker, P., Hughes, R. B., Arthur, A., Powers, L. E., \& Curry, M. A. (2009). Development of an accessible audio computer-assisted self-interview (A-CASI) to screen for abuse and provide safety strategies for women with disabilities. Journal of Interpersonal Violence, 24(5), 795-818.

Petersilia, J. R. (2001). Crime victims with developmental disabilities: A review essay. Criminal Justice and Behavior, 28(6), 655-694.

Platt, L., Powers, L., Leotti, S., Hughes, R. B., Robinson-Whelen, S., Osburn, S., . . Nicolaidis, C. (2017). The role of gender in violence experienced by adults with developmental disabilities. Journal of Interpersonal Violence, 32(1), 101-129.

Saxton, M., Curry, M. A., Powers, L. E., Maley, S., Eckels, K., \& Gross, J. (2001). "Bring my scooter so I can leave you": A study of disabled women handling abuse by personal assistance providers. Violence Against Women, 7, 393-417. 
Saxton, M., McNeff, E., Powers, L., Curry, M. A., Limont, M., \& Benson, J. (2006). We're all little John Waynes: A study of disabled men's experience of abuse by personal assistants. Journal of Rehabilitation, 72, 3-13.

Stack, E. E., \& McDonald, K. (2018). We are "both in charge, the academics and selfadvocates": Empowerment in Community-Based Participatory Research. Journal of Policy and Practice in Intellectual Disabilities, 15(1), 80-89.

Nnawulezi, N., Sullivan, C. M., Marcus, S., Young, L., \& Hacskaylo, M. (2019). Negotiating participatory research processes with domestic violence program staff to obtain ecologically valid data. Journal of interpersonal violence, 34(23-24), 4817-4837.

Vaughan, C., Gill-Atkinson, L., Devine, A., Zayas, J., Ignacio, R., Garcia, J., Bisda, K., Saldago, J., \& Marco, M. J. (2020). Enabling action: Reflections upon inclusive participatory research on health with women with disabilities in the Philippines. American Journal of Community Psychology, 66(3-4), 370-380.

Wright, C. A., \& Diener, M. L. (2020). Advancing participant-oriented research models in research intensive universities. Journal of Higher Education Outreach and Engagement, 24(1), 143-152. 